\title{
Sexual Conflict Arising from Extrapair Matings in Birds
}

\author{
Alexis S. Chaine ${ }^{1}$, Robert Montgomerie' ${ }^{2}$, and Bruce E. Lyon ${ }^{3}$ \\ ${ }^{1}$ Station d'Écologie Expérimentale du Centre National de la Recherche Scientifique (CNRS), 09200 \\ Moulis, France \\ ${ }^{2}$ Department of Biology, Queen's University, Kingston, Ontario K7L 3N6, Canada \\ ${ }^{3}$ Department of Ecology and Evolutionary Biology, University of California, Santa Cruz, California 95064 \\ Correspondence: Iyon@biology.ucsc.edu
}

The discovery that extrapair copulation (EPC) and extrapair paternity (EPP) are common in birds led to a paradigm shift in our understanding of the evolution of mating systems. The prevalence of extrapair matings in pair-bonded species sets the stage for sexual conflict, and a recent focus has been to consider how this conflict can shape variation in extrapair mating rates. Here, we invert the causal arrow and consider the consequences of extrapair matings for sexual conflict. Extrapair matings shift sexual conflict from a simple two-player (male vs. female) game to a game with three or more players, the nature of which we illustrate with simple diagrams that highlight the net costs and benefits of extrapair matings to each player. This approach helps identify the sorts of traits that might be under selection because of sexual conflict. Whether EPP is driven primarily by the extrapair male or the within-pair female profoundly influences which players are in conflict, but the overall pattern of conflict varies little among different mating systems. Different aspects of conflict are manifest at different stages of the breeding cycle and can be profitably considered as distinct episodes of selection caused by conflict. This perspective is illuminating both because conflict between specific players can change across episodes and because the traits that evolve to mediate conflict likely differ between episodes. Although EPP clearly leads to sexual conflict, we suggest that the link between sexual conflict and multiple paternity might be usefully understood by examining how deviations from lifetime sexual monogamy influence sexual conflict.

$\mathrm{T}^{\mathrm{h}}$ he development of genetic tools for determining parentage fundamentally altered our understanding of animal mating systems (Jeffreys et al. 1985; Avise 1996; Reynolds 1996) and provided invaluable insights into the consequences and causes of females mating with more than one male. Particularly for the study of birds, these methods revealed that social pair bonds often fail to match the actual patterns of copulations that produced offspring (Gowaty and Karlin 1984; Birkhead and Møller 1992; Reynolds 1996; Petrie and Kempenaers 1998), revolutionizing the study of avian mating systems. Extensive research and two recent reviews point out the progress we have made in this field and show how little we still understand extrapair behavior (Griffith et al. 2002; Westneat and Stewart 2003).

Editors: William R. Rice and Sergey Gavrilets

Additional Perspectives on The Genetics and Biology of Sexual Conflict available at www.cshperspectives.org

Copyright (C) 2015 Cold Spring Harbor Laboratory Press; all rights reserved; doi: 10.1101/cshperspect.a017590

Cite this article as Cold Spring Harb Perspect Biol 2015;7:a017590 
A.S. Chaine et al.

In the 1960s, David Lack compiled what was then known about mating systems in birds and concluded that $>90 \%$ of species were monogamous, a pattern that provided an early framework for the development of mating system theory (Lack 1968; Orians 1969; Emlen and Oring 1977). When it was later discovered that sexual mating patterns did not match the social mating systems that Lack described, the field was turned on its head (Westneat et al. 1990; Avise 1996; Reynolds 1996; Zeh and Zeh 2001). In extreme cases, the mismatch between the social and sexual mating systems is nothing short of spectacular; in fairywrens (Malurus species) that are socially monogamous, cooperatively breeding species with helpers, the extrapair paternity (EPP) rate can exceed $75 \%$ of all offspring and $95 \%$ of all broods (Mulder et al. 1994). In socially monogamous birds, in general, the rate of EPP is typically on the order of $10 \%$ of offspring and $20 \%$ of broods (Griffith et al. 2002), but variation among species, and even populations within species, is extensive (Arnold and Owens 2002; Griffith et al. 2002). The occurrence of EPP has profound consequences for the evolution of social behavior, both because it alters the scope for the action of sexual selection (Webster et al. 1995; Sheldon and Ellegren 1999) and because it results in males often providing parental care to offspring they have not sired (Davies et al. 1992; Westneat and Sherman 1993).

Even in taxa with mating systems other than social monogamy, or in which there is no obvious pair bond, the ability to determine parentage genetically was revolutionary, allowing precise estimates of male reproductive success when females mate multiply. That focus on multiple mating also catalyzed an interest in sexual selection from the female's perspective, whereas previous attention had been strongly biased toward males and male traits. More specifically, it raised the questions as to why females would pursue and benefit from matings outside the social pair bond (Westneat et al. 1990; Petrie and Kempenaers 1998), and why a female would benefit from mating with more than one male for a given clutch or litter. This new focus on females brought attention to the issue of polyandry more generally (Jennions and Petrie
2000; Simmons 2005; Parker and Birkhead 2013; Pizzari and Wedell 2013).

Recently, the assumption that females control mating patterns, and thus that polyandry and EPP can be universally understood from the perspective of fitness benefits to females, has been questioned (Westneat and Stewart 2003). Focusing specifically on EPP, Westneat and Stewart (2003) suggested that, in some taxa, EPP could be driven entirely by benefits to the extrapair-seeking male. They also suggested that many aspects of EPP can be profitably explored from the perspective of sexual conflict, as had Petrie and Kempenaers (1998) before them. Previous interest in the relation between EPP and sexual conflict in birds was focused particularly on trying to explain the incidence and frequency of EPP within and among species. Westneat and Stewart (2003) recognized that that link was indirect. Instead, they suggested that sexual conflict theory might help us to identify traits that could arise from conflict and that those traits might inform the search for a general explanation of the huge variation in EPP rates both among and within bird species.

Sexual conflict, the conflicting fitness interests of males and females during mating (Parker 1979; Rice 1998; Arnqvist and Rowe 2005), can lead to antagonistic coevolution between the traits expressed in males and those expressed in females, traits that in some way influence mating outcomes. Traits in males and females are ultimately the drivers of conflict, and, reciprocally, conflict fuels further trait evolution. Sexual conflict theory is useful because it can potentially explain the evolution and maintenance of traits that are otherwise difficult to understand (Arnqvist and Rowe 2005). Thus, studies often examine the factors and traits that underlie different aspects of sexual conflict, as well as the types of morphological and behavioral traits that result from selection caused by the sexual conflict itself.

In this article, we build on the foundation provided by Westneat and Stewart (2003). They proposed that sexual conflict can help to explain variation in the occurrence of EPP among species and populations (Westneat and Stewart 2003). Here, we invert the focus and seek 
to understand the consequences that EPP can have for sexual conflict and the relation between EPP and other drivers of sexual conflict. Thus, we examine the players involved in the sexual conflict generated by EPP and the costs and benefits that underpin the conflicts among the different players. We point out that different conflicts are involved in the different stages of a single bout of reproduction, and we suggest that these represent sequential periods of conflict, each of which is a different episode of selection generated from that conflict. We then place these patterns of conflict into a broader context by contrasting how different patterns of fidelity and infidelity (including EPP) during a lifetime of mating can influence sexual conflict. Our review focuses on birds as examples, both because they have been extensively studied with respect to EPP and because they have been the subjects of most of our own research. Our goal, however, is to provide a framework for understanding trait evolution under the influence of sexual conflict caused by females mating multiply in any animal species.

\section{THE PLAYERS}

Sexual conflict is often seen as a conflict between males and females. However, when females mate with more than one male, sexual conflict necessarily becomes a multiplayer game. The players include at least the pair female, pair male, and extrapair male (Petrie and Kempenears 1998; Rice 1998; Westneat and Stewart 2003; Alonzo and Pizzari 2013). In some cases, the female paired with the extrapair male may also suffer fitness losses because of her mate's activities, in which case, the conflict becomes a fourplayer game (Petrie and Kempenaers 1998). Indeed, in specific cases, more than four players may also be involved if, for example, there are multiple extrapair males, multiple females are affected by the extrapair behavior in a polygynous system, or EPP affects the fitness of nonbreeding individuals, such as helpers in cooperative breeders.

The complexities involved in the sorts of conflicts generated by EPP can be usefully illustrated with conflict-of-interest diagrams that show all of the players involved (Fig. 1; see also Petrie and Kempenaers 1998; Rice 1998). For example, the addition of an extrapair male to the simple conflict between the sexes in a mated pair potentially creates two sexual conflicts-one between the female and her mate and the other between the same female and the extrapair male-as well as intrasexual conflict between the two males (Fig. 1). The dynamics of the conflict between any two of these players can be affected by the other conflicts of interests in the triad (Westneat and Stewart 2003). Thus, to fully understand how sexual conflict affects trait evolution, we need to consider all conflict interactions, including how intrasexual conflict between males influences

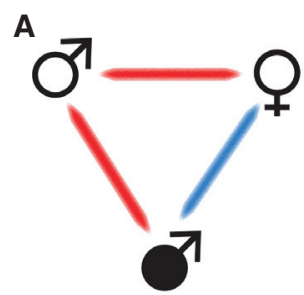

Female-driven EPP

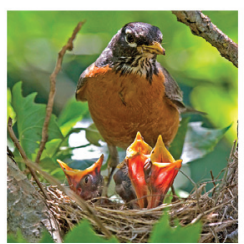

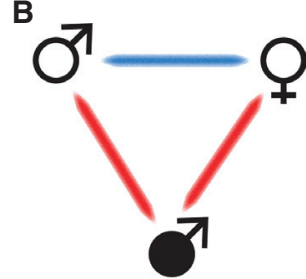

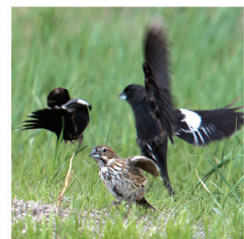

Male-driven EPP

Figure 1. Conflicts of interests between males and females over the occurrence of extrapair matings in socially monogamous mating systems. Symbols for extrapair males are solid black. Red bars join individuals that are in conflict over the occurrence of extrapair matings, whereas blue bars join individuals that agree on the optimal level (zero for male-driven) of extrapair mating. Two different socially monogamous systems are shown here: $(A)$ When females benefit from EPP (i.e., EPP is female driven), the female and EPP male both benefit from EPP and are in conflict with the within-pair male (e.g., American robin Turdus migratorius), and ( $B)$ when EPP is solely driven by the fitness interests of the extrapair male (i.e., EPP is male driven), both the female and within-pair male are in conflict with the extrapair male (e.g., lark bunting Calamospiza melanocorys shown here with a male attempting an EPC while the pair male tries to fend him off ). (Both photos courtesy of B. Lyon.) 


\section{A.S. Chaine et al.}

conflict between the sexes. It is important to recognize that extrapair matings generate different conflicts that manifest themselves at successive stages of reproduction (e.g., conflict over mating, fertilization, and postfertilization investment; see the section Episodes of Conflict over EPP: When and over What?). In this first section, we use conflict-of-interest diagrams to focus only on the conflict over the occurrence of extrapair copulations (EPCs) and not during the subsequent episodes of reproduction. We provide details on only one stage of reproduction because the basic nature of the conflict can change across episodes (see below), and
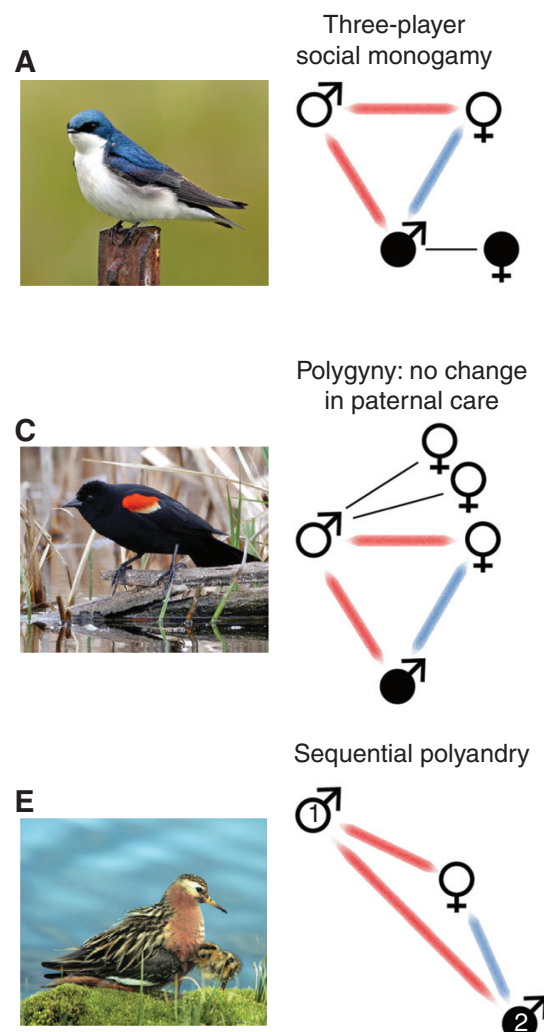

hence a single diagram is often specific to one episode.

Our conflict-of-interest diagrams (Fig. 1) illustrate simply whether or not there is conflict between two players; we ignore the strength of the conflict and avoid assumptions about which player causes the conflict, hence the lack of arrows denoting a direction of conflict. Blue links indicate when two players both share the same optimal level (zero for male-driven) of extrapair mating, red links denote conflicts of interest over the occurrence of that mating, and, in Figure 2, thin black lines denote pairs of socially interacting individuals whose joint fitness inter-
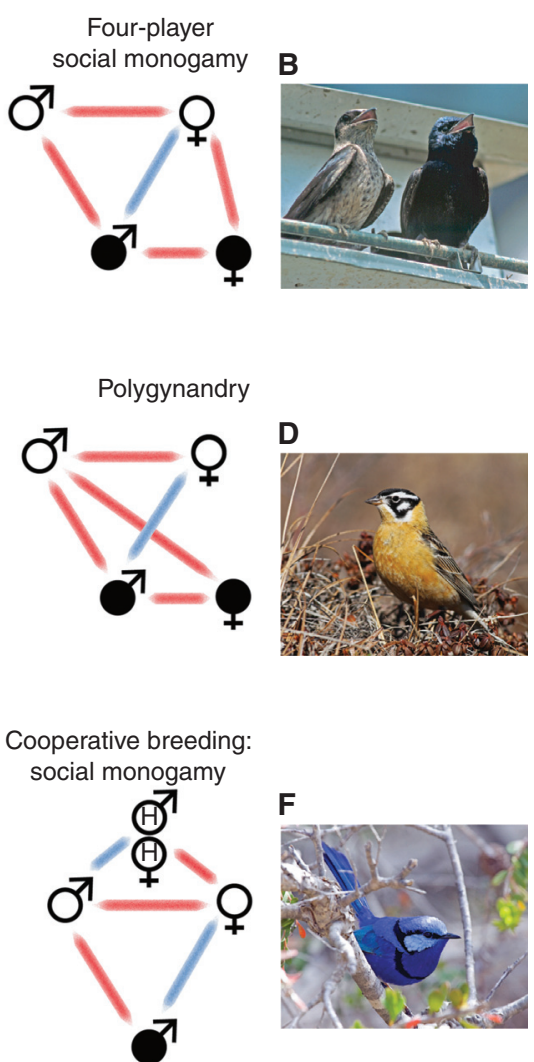

Figure 2. Conflicts of interests between focal males and females in relation to breeding system. Symbols for extrapair males and their social mates in solid black. Red bars join individuals that are in conflict over the occurrence of the extrapair matings, whereas blue bars join individuals that share the same optimal level (zero for male-driven) or extrapair mating; thin black lines indicate no particular costs or benefits. All cases shown involve female-driven EPP, in which the female benefits from the extrapair mating. Photos show one example species of each mating system: (A) Tree swallow (Tachycineta bicolor), (B) purple martin (Progne subis), $(C)$ redwinged blackbird (Agelaius phoeniceus), (D) Smith's longspur (Calcarius pictus), (E) red phalarope, and $(F)$ splendid fairywren (Malurus splendens). (All photos courtesy of B. Lyon, except Smith's longspur, which is provided by Ian Davies.) 
ests are not affected by the extrapair mating. The two males will typically be in conflict over the occurrence of the EPCs because they compete to fertilize the same ova-usually a zero-sum game. Although male-male cooperation over matings with a single female is theoretically feasible (e.g., when courtship and copulation with different males greatly stimulate female fecundity [Alonzo and Pizzari 2013]), this idea remains to be tested empirically.

These conflict-of-interest diagrams help to illustrate how conflict changes under different social scenarios. A fundamental debate, for example, is whether or not EPP benefits females (Mulder et al. 1994; Westneat and Stewart 2003; Arnqvist and Kirkpatrick 2005; Griffith 2007; Dunn et al. 2013). The sex that promotes the occurrence of an extrapair mating also critically influences the pattern of sexual conflict over such matings: Male- and female-driven EPP result in opposite patterns of conflict over whether extrapair matings should occur (Petrie and Kempenears 1998) and hence opposite patterns of selection on traits (Fig. 1A,B). Importantly, sexual conflict over EPP occurs whether it is male or female driven; what changes is whether the conflict is within the pair or between the extrapair male and both members of the pair (Fig. 1A,B).

In socially monogamous species with female-driven EPP, the female and extrapair male share a benefit from EPP, whereas the female and her mate are in conflict over the occurrence of the EPC (Fig. 1A). Thus, we expect to see traits that enhance the extrapair male's ability to court the female, the pair male's ability to guard his mate, and the female's ability to evade mate guarding and thereby sneak away to copulate with an extrapair male. Mate guarding by the within-pair male appears to be particularly widespread (Møller and Birkhead 1991; Kokko and Morrell 2005; Pedersen et al. 2006), but there is also some evidence that the extrapair male and pair female use tactics to enhance their copulation success. Superb fairywren (Malurus cyaneus) females, for example, go on extrapair forays to seek EPCs before dawn (Double and Cockburn 2000), presumably to avoid detection by their social mate.
Intriguingly, male fairywrens seek EPCs with a unique display behavior-a flower petal display - that they use only when courting females seeking EPCs (Mulder 1997; Karubian and Alvarado 2003). Alternatively, Dunnock (Prunella modularis) females fly quickly to try to "lose" their social mate when they are seeking extrapair mates, and copulations with those extrapair males are exceptionally rapid and cryptic ( $\mathrm{Da}-$ vies 1992). Females may also adopt countertactics to incite male-male competition and thereby thwart tenacious mate guarding by their mates (Montgomerie and Thornhill 1989); female bearded reedlings (Panurus biarmicus), for example, produce a call that attracts the attention of multiple extrapair males and this has been interpreted as a means for the female to increase the frequency of EPCs (Hoi 1997).

When EPP is driven by extrapair males, the female and her mate might both benefit from preventing EPCs, and thus both would be in conflict with an extrapair male (Fig. 1B). In this situation, we expect evidence for forced or coerced copulations by the extrapair male and cooperation between the pair members to prevent them. Females, for example, might call to attract the attention of their mate when an extrapair male approaches in pursuit of copulations. There are no clear avian examples of such tactics, but female moose (Alces alces) call to attract the attention of the dominant male when subordinate males attempt to force copulations (Bowyer et al. 2011). Extrapair males, on the other hand, should evolve morphologies or behaviors to force matings that females are trying to avoid. Thus, cloacal protuberances in male birds may have been favored specifically because of benefits they provide in securing EPP, as they occur most commonly in species in which there is sperm competition because of extrapair matings (Briskie 1993; Tuttle et al. 1996). A few taxa of birds, particularly waterfowl and ratites, also have penises and these structures may have evolved particularly to help extrapair males overcome female defenses (Briskie and Montgomerie 1997; Brennan et al. 2007).

Variation in breeding system (i.e., in patterns of association between the sexes and parentage) might be expected to impact how 
A.S. Chaine et al.

EPP influences sexual conflict because different breeding systems vary in the numbers of socially interacting individuals. It is therefore surprising that the overall patterns of conflict over the occurrence of extrapair matings would appear to be similar across breeding systems (Fig. 2A-F). On reflection, this makes sense because EPP is about the sexual (genetic) patterns of reproduction, and these are actually quite similar across social systems. The patterns of conflict only differ when EPP influences either the social patterns or parental care trade-offs among more than one male and female, such as in social polygynandry (Fig. 2D), when males provision offspring at more than one nest (Davies 1992; Briskie et al. 1998). Likewise, social polyandry can lead to mixed paternity in one or more clutches (Fig. 2E), either because females mate simultaneously with multiple males or because sperm from a first reproductive bout can be stored and sire offspring from a second clutch, a pattern documented for role-reversed species like spotted sandpipers (Actitis macularius [Oring et al. 1992] or red phalaropes (Phalaropus fulicarius [Dale et al. 1999]). Although these conflict patterns resemble the basic interactions in social monogamy, a key difference in polygnandrous and polyandrous breeding systems is that all of the males are socially paired with the same female, and the conflict thus comes from within the breeding association, not from outside.

In one other breeding system, cooperative breeding, the pattern of sexual conflict among breeding adults is similar to that in social monogamy, but the occurrence of EPP has a special influence on other social group members, the helpers (Fig. 2F). The presence of extrapair offspring in the brood reduces the relatedness between helpers and the offspring they are helping to raise, thus reducing the indirect benefits from helping (Charnov 1981). This creates conflict between helpers and their mother, which, in turn, should favor helpers that discourage the occurrence of extrapair matings. How cooperative breeding remains stable under the extremely high levels of EPP observed in some fairywrens (Malurus species) is puzzling. Possibly, females show very high fidelity to the same extrapair male across years, in which case, help- ers would often be assisting their mother to raise full siblings.

\section{BENEFITS AND COSTS OF EPP AS DRIVERS OF CONFLICT}

Sexual conflict occurs because the fitness interests of the sexes can differ during the various stages of reproduction. Thus, to understand how and why EPP generates sexual conflict, and how this source of conflict compares with other forms of sexual conflict, we need to understand the costs and benefits of the extrapair matings to the different players.

The benefits that males gain from extrapair matings have long been clear (Trivers 1972): via EPP, males sire more offspring than would otherwise be possible. Any benefits gained by the extrapair male are thought to lead to direct fitness costs for the within-pair male because the within-pair male then sires fewer offspring than he would otherwise. But EPP may cause females to increase their investment, either through the stimulatory effects of ejaculates from multiple males (Alonzo and Pizzari 2013) or when females engage in EPP to upgrade the genetic quality of their offspring, resulting in differential allocation of maternal care (Burley 1988). Thus, changes in female investment should be considered when evaluating the fitness costs to the pair male and the effects on his contribution to parental care (Sheldon 2000, 2002).

For females, extrapair matings potentially bring a wide variety of direct and indirect fitness benefits, but the importance of indirect benefits remains controversial (Arnqvist and Kirkpatrick 2005; Griffith 2007). Direct benefits of EPC can accrue from an increase in the number of fertilized ova (e.g., when the pair male is infertile or has limited sperm available [Sheldon 1994]), access to more resources (e.g., extrapair male's territory or paternal care [Davies 1992; Briskie et al. 1998]), and a reduction in harassment by those males seeking EPCs (Rowe 1992; Gowaty and Buschhaus 1997). In species with sexually selected infanticide by males, females that mate multiply (via polyandry or EPP) might reduce the risk of infanticide of their eggs or offspring if infanticide is performed by 
males that have not copulated with the female (Agrell et al. 1998; Soltis et al. 2000). Potential indirect benefits include the genetic benefits that accrue from an increase in the quality, rather than quantity, of offspring (good genes in a viability or sexual context [Slayter et al. 2012; Madsen et al 1992] or genetic complementarity [Zeh and Zeh 2006]), an increase in the genetic diversity of offspring (Slayter et al. 2012; Parker and Birkhead 2013), or a reduction of inbreeding depression when females are socially paired with a relative (Blomqvist et al. 2002; Cornell and Tregenza 2007). Note that these female benefits are identical to benefits from polyandry generally (i.e., when females mate with more than one male during a reproductive bout [Schlicht and Kempenaers 2011; Slayter et al. 2012; Parker and Birkhead 2013]).

There are also likely to be fitness costs to females from extrapair matings, especially when EPP is driven solely by the fitness interests of the extrapair male, such as when the copulations are forced or coerced (Westneat and Stewart 2003). In addition to the risk of injury or transfer of sexually transmitted diseases during mating, the female suffers a potential indirect loss of fitness by having some of her offspring sired by a nonpreferred male - a cost that is the inverse of the benefits a female gains when EPP is female driven. Females may also suffer a cost due to the loss of parental care from her social mate when he suspects EPP (Sheldon 2002; Griffin et al. 2013). Finally, there are also potential costs to the female mated to a male who seeks EPCshis extrapair matings could increase her risk of contracting sexually transmitted diseases or could result in lower investment from her mate if he invests time seeking extrapair mates (Magrath and Elgar 1997; Magrath and Komdeur 2003). In theory, the extrapair male's mate could also suffer fitness losses if the extrapair male allows the other female to access his territorial resources or if he provides food to her offspring.

\section{EPISODES OF CONFLICT OVER EPP - WHEN AND OVER WHAT?}

In their broad survey of the natural history of sexual conflict, Arnqvist and Rowe (2005) noted that sexual conflict can occur during any interaction between a male and female, not just when deciding whom to mate with. They identified three main types of interactions as the "components" of conflict: (1) conflict before copulation, (2) conflict during the period from copulation to fertilization of the zygote, and (3) conflict after fertilization, over parental investment. We suggest that these three components delineate clear episodes of selection because they are temporally distinct bouts that connect in a temporal sequence to influence lifetime fitness (Arnold and Wade 1984; Moore 1990; McGlothlin 2010). Thinking about episodes of selection helps clarify how these different periods of conflict are linked through their effects on fitness, how selection driven by conflict might be resolved, and how different types of traits are often favored during the different episodes.

The different episodes of conflict differ in some critical ways with respect to EPP. First, the basic nature of the conflict can invert from one episode to the next. For example, with maledriven EPP, the female and her mate should cooperate to prevent extrapair mating attempts, but when an EPC does occur and is detected by the pair male, it can trigger conflict between the paired male and female over postfertilization investment. Males should not invest in offspring they have not sired whether that EPP was male or female driven. Second, the traits that mediate conflict (i.e., that evolve in response to conflict) differ across the episodes, both in the types of traits and in the degree to which they show canalization or plasticity among mating roles. The same traits that mediate conflict over the decision to mate are not likely to be the same as those that mediate fertilization success or parental investment.

Likewise, plastic traits are probably more useful in some episodes than in others. Traits shows plasticity when their expression depends on the mating role in which they are manifest (e.g., different expression in extrapair versus within-pair males) (Fig. 1) (Petrie and Kempenaers 1998; Ball and Parker 2003; Westneat and Stewart 2003; Parker 2006; Alonzo and Pizzari 2013). Role-specific traits must necessarily be flexible, and they also require an assessment 
A.S. Chaine et al.

mechanism that can link trait expression to its specific role. Behavioral traits provide the simplest way to achieve role flexibility. Thus, plasticity may be more likely in episodes in which behavior is important (e.g., premating decisions and parental care), whereas canalized traits may be more likely when physiology, rather than behavior, is the mediator of conflict (e.g., fertilization success).

Before copulation, there is sexual conflict that favors traits in the extrapair male that increase the success of his extrapair mating attempts, in the within-pair male that decrease the copulation success of the extrapair male, and in the females that enhance or decrease the success of extrapair matings, depending on whether or not the female benefits from those matings. Because the premating episode mainly involves behavioral interactions between individuals, there is much potential for role-specific trait expression and ample evidence for differences in the behaviors of the extrapair and within-pair males (e.g., territorial vs. sneaker males).

Once an EPC occurs, the conflict shifts to interactions that influence fertilization success within the female's reproductive tract. Sperm number and characteristics as well as ejaculate properties mediate that conflict for males, whereas sperm storage structures and reproductive tract secretions play a role in mediating the conflict over fertilization success for females (Birkhead et al. 1993; Briskie and Montgomerie 1993). Males thus have the opportunity to adjust sperm number or ejaculate size specifically in the context of pursuing EPP (Parker 1990; Birkhead and Fletcher 1992; Birkhead et al. 1995; Pizzari et al. 2003).

The third episode of conflict over EPP arises after fertilization and influences parental investment in offspring. Multiple paternity in a brood potentially alters sexual conflict over parental investment because it reduces the fitness the social male could have gained from the current reproductive bout. However, it is debatable whether this translates into a reduction in paternal care (e.g., Sheldon 2002; Griffin et al 2013), although there are clearly conflicts of interest over the fitness consequences of EPP. For example, theory suggests that there can be situations under which EPP does not affect the optimal parental investment of the male (Westneat and Sherman 1993; Griffin et al. 2013). On the other hand, there is some evidence that males, on average, invest less parental care in species with higher rates of EPP (reviewed in Griffin et al. 2013). Finally, extrapair males would be expected to benefit if they can cause an increased investment by both parents beyond their optimal levels, but it is unclear what mechanisms would enable them to do so facultatively.

\section{VARIATION IN MATING PATTERNS DRIVES EPISODES OF SEXUAL CONFLICT}

In this section, we focus particularly on how different mating patterns (including EPP) affect different episodes of conflict. To do this, we distinguish four basic mating patterns that differ in the degree of mating fidelity and the types of sexual conflict they generate (Fig. 3). At one extreme is lifetime sexual monogamyone male and one female social partner for life, and they mate only with each other. This mating pattern is intriguing because, in theory, sexual conflict should be nonexistent because the lifetime fitness interests of a paired male and female are identical and entirely dependent once pairing has occurred (Rice and Holland 1997). Selection experiments with Drosophila support this theory-selection lines with experimentally imposed lifetime monogamy showed dramatic reductions in measures of sexual conflict relative to lines with the normal polyandrous pattern of mating (Holland and Rice 1999). Theory and comparative studies also suggest that lifetime sexual monogamy is crucial for the evolution of some strong forms of altruism, such as the helping behavior observed in social insects and some birds (Hughes et al. 2008; Cornwallis et al. 2010; Boomsma 2013).

Any deviations from lifetime sexual monogamy set the stage for sexual conflict (Holland and Rice 1997) in two different ways (Fig. 3): sexually monogamous matings within a reproductive bout, but males and females change mates between reproductive bouts, or females mate polyandrously within a given reproductive bout. Polyandry within a reproductive bout 


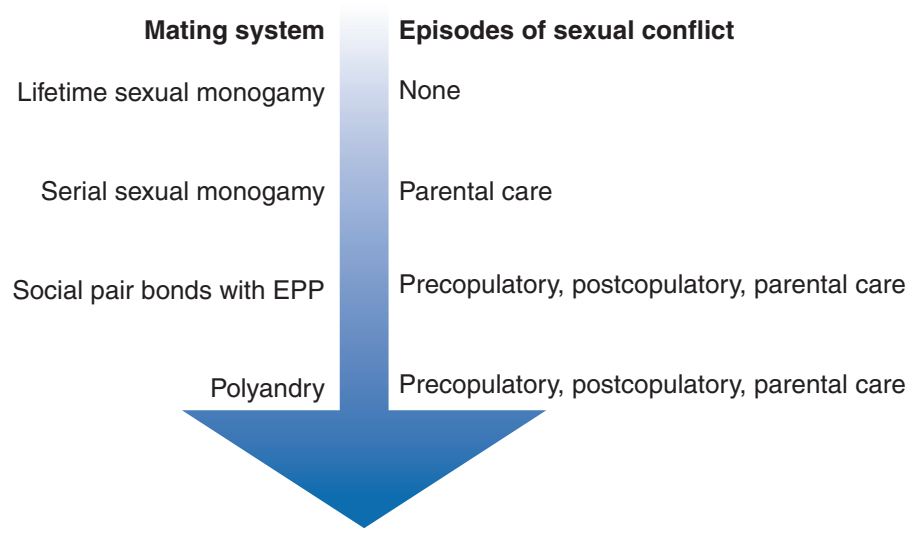

Figure 3. Deviation from lifetime monogamous mating creates sexual conflict, but different mating patterns create different patterns of conflict. All deviations from lifetime monogamy potentially create sexual conflict over how much a female invests in a given reproductive bout, but polyandrous matings (including EPP) are required for conflict over both matings and fertilization.

occurs in species both with and without pair bonds; the former is the special context referred to as extrapair matings, which gives rise to EPP. This sexual conflict framework based on mating patterns is useful because it allows us to partition the different factors that contribute to sexual conflict and identify which of them apply generally to all mating systems (except lifelong sexual monogamy) and which are unique to specific mating systems.

A couple of patterns emerge. First, sexual conflict over reproductive investment is ubiquitous in all systems in which lifetime monogamy does not occur (Fig. 3) - even without polyandrous matings, traits in males that enable them to extract levels of female parental investment above the female's optimum can be favored, including ejaculate components that manipulate females to increase their investment in the sire's brood (Chapman 2001; Wolfner 2002; Wedell et al. 2006), and imprinted genes that, when inherited from the male, cause an embryo to increase the extent of resource extraction from its mother (Haig and Westoby 1989; Haig 2000). Second, polyandrous matings and multiple paternity (including EPP) in a given clutch or litter generate two additional episodes of sexual conflict that are absent when females mate with only one male in a given breeding seasonsexual conflict over both copulations and fertil- ization (Fig. 3). That general polyandry and EPP share these distinctive episodes of conflict supports the notion that EPP is simply a special case of polyandry in matings that involve pair bonds (Schlicht and Kempenaers 2011). For the conflict over copulations, which individuals are in conflict will depend on whether EPP is female or male driven, and this will affect the types of traits that are favored. For the conflict over fertilization, the scope for flexible role-specific traits in the competing males is probably limited with regard to sperm morphology, but it could be expressed as variation in copulation rate (Briskie 1993) or ejaculate size (Parker 1990; Birkhead and Fletcher 1992).

Finally, conflict that affects male parental care is clearly influenced by EPP. This is generally true because any deviation from lifetime sexual fidelity favors traits in both sexes that lead to increased investment in a given bout by the other sex. Mechanisms to achieve this increased investment include products in male ejaculates that alter female investment (Reinhardt et al. 2009) or genomic imprinting that alters offspring physiology or behavior to extract more resources from the female (and possibly the pair male [Haig and Westoby 1989; Haig 2000]). However, when sexual conflict is driven by EPP, a reduction in parental investment by the within-pair male is favored, and 
A.S. Chaine et al.

that would exacerbate the already present conflict over optimal parental investment by each parent. Of course, this only applies to pairbonded species that show male parental carea situation that is widespread in birds but not ubiquitous (Schwagmeyer et al. 1999; Cockburn 2006).

\section{CONCLUSIONS}

One of our goals in writing this review has been to give some structure to thinking about the kinds of traits that are expected to be favored in response to the sexual conflict that arises when there is extrapair mating in birds. Clearly, many of these traits are common to conflict when females mate multiply, whether or not there is a social mating system that includes extrapair matings. We see this as an important, and often neglected, point both because there is really not very much that is special about EPP in the context of sexual conflict and because those few traits that are special are all relevant to conflict over parental care. This is perhaps not so surprising because it is biparental care that underlies the structure of socially monogamous mating systems (or polygyny with male care), and the resolution of those conflicts might be an important source of selection on the evolution of fidelity in general.

Most research on the incidence of extrapair mating — in birds, at least — has focused on trying to explain why males and females might gain a fitness advantage by seeking EPCs. In part because promiscuity is probably the ancestral state (Corwallis et al. 2010), we suggest that it might be profitable to look, instead, at factors that influence the evolution of fidelity in birds and the reduction of sexual conflict caused by EPP. Although within-pair sexual fidelity might evolve for a variety of reasons (Black 1996), there would certainly be advantages from conflict reduction in the short term that might well outweigh the disadvantages of infidelity, some of which we have listed in this review. Thus, we suggest that, in species with biparental care in particular, models that consider the benefits of fidelity balanced against the costs of extrapair mating, including costs due to sex- ual conflict, might help us to understand the still bewildering incidence of EPP within and among bird species.

In a similar vein, it has been clear for a long time that demography could have a major influence on the value of extrapair mating in birds. As Arnold and Owens (2002) showed, about half of the variation in rates of EPP among bird species can be explained solely by the rates of adult mortality. Two factors might explain this pattern. First, a prerequisite for future cooperation between a breeding pair is that both the male and female of a pair survive to the following year, a probability that decreases exponentially with increased mortality rates (i.e., joint survival $\propto$ mortality $\left.^{2}\right)$. Second, longerlived species simply have more opportunity to benefit from the advantages of sexual fidelity (i.e., more years of enjoying the benefits) and, as a consequence, have lower rates of EPP and EPP-driven sexual conflict-a notion that remains to be explored. This, again, suggests that an exploration of the factors that influence the evolution of fidelity could be a profitable way to understand the distribution of EPP both within and among species. As we have outlined above, traits that arise from sexual conflict vary during the breeding cycle, involving distinct episodes of selection before copulation, between copulation and fertilization, and during the period of parental care. Consideration of the costs and benefits of fidelity during each of these episodes is important because these will vary, directly influencing the benefits of sexual fidelity during each episode.

As has been frequently pointed out, there are many interesting parallels between the natural histories (social monogamy, biparental care) and modes of communication (vocal and color vision) in birds and humans (Birkhead 2012). As for birds, EPP in humans creates sexual conflict that is resolved to some extent by behaviors (mate guarding, kin recognition), physiologies (concealed ovulation), and the advantages of sexual fidelity, particularly with respect to parental care (Benshoof and Thornhill 1979; Burley 1979; Alvergne et al. 2009). We have focused this review on sexual conflict in birds, but we suggest that the perspectives we 
have taken here-on the players, changes in conflict across episodes of the breeding cycle, and the traits that evolve to reduce conflictare generally applicable to the study of sexual conflict in any organism in which females mate multiply.

\section{ACKNOWLEDGMENTS}

Our research on the mating systems of birds is supported by grants from Agence Nationale de la Recherche (ANR)-LabEx "Tulip" and ANRProgramme Jeunes Chercheuses Jeunes Chercheurs (JCJC) "NetSelect" (A.S.C.), the Natural Sciences and Engineering Research Council of Canada and Queen's University (R.M.), and the National Science Foundation, National Geographic Society, and the University of California (A.S.C., B.E.L.).

\section{REFERENCES}

Agrell J, Wolff JO, Ylönen H. 1998. Infanticide in mammals: Strategies and counter-strategies. Oikos 84: 507-517.

Alonzo SH, Pizzari T. 2013. Selection on female remating interval is influenced by male sperm competition strategies and ejaculate characteristics. Phil Trans Roy Soc B 368: 20120044.

Alvergne A, Faurie C, Raymond M. 2009. Father-offspring resemblance predicts paternal investment in humans. Anim Behav 78: 61-69.

Arnold KE, Owens IPF. 2002. Extra-pair paternity and egg dumping in birds: Life history, parental care and the risk of retaliation. Proc Roy Soc B 269: 1263-1269.

Arnold SJ, Wade MJ. 1984. On the measurement of natural and sexual selection: Theory. Evolution 38: 709-719.

Arnqvist G, Kirkpatrick M. 2005. The evolution of infidelity in socially monogamous passerines: The strength of direct and indirect selection on extrapair copulation behavior in females. Am Nat 165: S26-S37.

Arnqvist G, Rowe L. 2005. Sexual conflict. Princeton University Press, Princeton, NJ.

Avise JC. 1996. Three fundamental contributions of molecular genetics to avian ecology and evolution. Ibis 138: $16-25$.

Ball MA, Parker GA. 2003. Sperm competition games: Sperm selection by females. J Theor Biol 224: 27-42.

Benshoof L, Thornhill R. 1979. The evolution of monogamy and loss of estrus in humans. J Soc Biol Str 2: 95-106.

Birkhead T. 2012. Bird sense. Bloomsbury, London.

Birkhead TR, Fletcher F. 1992. Sperm to spare? Sperm allocation by male zebra finches. Anim Behav 43: 10531055.
Birkhead TR, Møller AP. 1992. Sperm competition in birds: Evolutionary causes and consequences. Academic, London.

Birkhead TR, Briskie JV, Møller AP. 1993. Male sperm reserves and copulation frequency in birds. Behav Ecol Sociobiol 32: 85-93.

Birkhead TR, Fletcher F, Pellatt EJ, Staples A. 1995. Ejaculate quality and the success of extra-pair copulations in the zebra finch. Nature 377: 422-423.

Black JM. 1996. Partnerships in birds: The study of monoga$m y$. Oxford University Press, Oxford.

Blomqvist D, Andersson M, Küpper C, Cuthill IC, Kis J, Lanctot RB, Sandercock BK, Székely T, Wallander J, Kempenaers B. 2002. Genetic similarity between mates and extra-pair parentage in three species of shorebirds. $\mathrm{Na}$ ture 419: 613-615.

Boomsma JJ. 2013. Beyond promiscuity: Mate-choice commitments in social breeding. Phil Trans Roy Soc B 368: 20120050.

Bowyer RT, Rachlow JL, Stewart KM, Van Ballenberghe V. 2011. Vocalizations by Alaskan moose: Female incitation of male aggression. Behav Ecol Sociobiol 65: 2251-2260.

Brennan PLR, Prum RO, McCracken KG, Sorenson MD, Wilson A, Read AF, Birkhead TR. 2007. Coevolution of male and female genital morphology in waterfowl. PLoS ONE 2: e418.

Briskie JV. 1993. Anatomical adaptations to sperm competition in Smith's Longspurs and other polygynandrous passerines. Auk 110: 875-888.

Briskie JV, Montgomerie R. 1993. Patterns of sperm storage in relation to sperm competition in passerine birds. Condor 95: 442-454.

Briskie JV, Montgomerie R. 1997. Sexual selection and the intromittent organ of birds. J Avian Biol 28: 73-86.

Briskie JV, Montgomerie R, Poldmaa T, Boag PT. 1998. Paternity and paternal care in the polygynandrous Smith's longspur. Behav Ecol Sociobiol 43: 181-190.

Burley N. 1979. The evolution of concealed ovulation. Am Nat 114: 835-858.

Burley N. 1988. The differential allocation hypothesis: An experimental test. Am Nat 132: 611-628.

Chapman T. 2001. Seminal fluid-mediated fitness traits in Drosophila. Heredity 87: 511-521.

Charnov EL. 1981. Kin selection and helpers at the nest: Effects of paternity and biparental care. Anim Behav 29: 631-632.

Cockburn A. 2006. Prevalence of different modes of parental care in birds. Proc Roy Soc B 273: 1375-1383.

Cornell SJ, Tregenza T. 2007. A new theory for the evolution of polyandry as a means of inbreeding avoidance. Proc Roy Soc B 274: 2873-2879.

Cornwallis CK, West SA, Davis KE, Griffin AS. 2010. Promiscuity and the evolutionary transition to complex societies. Nature 466: 969-972.

Dale J, Montgomerie R, Michaud D, Boag PT. 1999. Frequency and timing of extrapair fertilisation in the polyandrous red phalarope (Phalaropus fulicarius). Behav Ecol Sociobiol 46: $50-56$.

Davies NB. 1992. Dunnock behaviour and social evolution. Oxford University Press, Oxford. 
A.S. Chaine et al.

Davies NB, Hatchwell BJ, Robson T, Burke T. 1992. Paternity and paternal effort in dunnocks Prunella modularis: How good are male chick-feeding rules? Anim Behav 43: 729745.

Double M, Cockburn A. 2000. Pre-dawn infidelity: Females control extra-pair mating in superb fairy-wrens. Proc Roy Soc B 267: 465-470.

Dunn PO, Bollmer JL, Freeman-Gallant CR, Whittingham LA. 2013. MHC variation is related to a sexually selected ornament, survival, and parasite resistance in common yellowthroats. Evolution 67: 679-687.

Emlen ST, Oring LW. 1977. Ecology, sexual selection and the evolution of mating systems. Science 197: 215-223.

Gowaty PA, Buschhaus N. 1997. Functions of aggressive and forced copulations in birds: Female resistance and the CODE hypothesis. Am Zool 38: 207-225.

Gowaty PA, Karlin AA. 1984. Multiple maternity and paternity in single broods of apparently monogamous Eastern Bluebirds (Sialia sialis). Behav Ecol Sociobiol 15: 91-95.

Griffin AS, Alonzo SH, Cornwallis CK. 2013. Why do cuckolded males provide paternal care? PLoS Biol 11: e1001520.

Griffith SC. 2007. The evolution of infidelity in socially monogamous passerines: Neglected components of direct and indirect selection. Am Nat 169: 274-281.

Griffith SC, Owens IPF, Thuman KA. 2002. Extra pair paternity in birds: A review of interspecific variation and adaptive function. Mol Ecol 11: 2195-2212.

Haig D. 2000. The kinship theory of genomic imprinting Annu Rev Ecol Syst 31: 9-32.

Haig D, Westoby M. 1989. Selective forces in the emergence of the seed habit. Biol J Linn Soc 38: 215-238.

Hoi H. 1997. Assessment of the quality of copulation partners in the monogamous bearded tit. Anim Behav 53: 277-286.

Holland B, Rice WR. 1997. Cryptic sexual selection-more control issues. Evolution 51: 321-324.

Holland B, Rice WR. 1999. Experimental removal of sexual selection reverses intersexual antagonistic coevolution and removes a reproductive load. Proc Natl Acad Sci 96: 5083-5088.

Hughes WOH, Oldroyd BP, Beekman M, Ratnieks FLW. 2008. Ancestral monogamy shows kin selection is key to the evolution of eusociality. Science 320: 1213-1216.

Jeffreys AJ, Wilson V, Thein SL. 1985. Hypervariable "minisatellite" regions in human DNA. Nature 314: 67-73.

Jennions MD, Petrie M. 2000. Why do females mate multiply? A review of the genetic benefits. Biol Rev 75: 21-64.

Karubian J, Alvarado A. 2003. Testing the function of petalcarrying in the Red-backed Fairy-wren (Malurus melanocephalus). Еmu 1: 87-92.

Kokko H, Morrell LJ. 2005. Mate guarding, male attractiveness, and paternity under social monogamy. Behav Ecol 16: $724-731$.

Lack D. 1968. Ecological adaptations for breeding in birds. Chapman and Hall, London.

Madsen T, Shine R, Loman J, Hakansson T. 1992. Why do female adders copulate so frequently? Nature 355: $440-$ 441.
Magrath MJL, Elgar MA. 1997. Paternal care declines with increased opportunity for extra-pair matings in fairy martins. Proc Roy Soc B 264: 1731-1736.

Magrath MJL, Komdeur J. 2003. Is male care compromised by additional mating opportunity? Trends Ecol Evol 18: 424-430.

McGlothlin JW. 2010. Combining selective episodes to estimate lifetime nonlinear selection. Evolution 64: 13771385.

Møller AP, Birkhead TR. 1991. Frequent copulations and mate guarding as alternative paternity guards in birds: A comparative study. Behaviour 118: 170-186.

Montgomerie R, Thornhill R. 1989. Fertility advertisement on female birds: A means of inciting male-male competition. Ethology 81: 209-220.

Moore AJ. 1990. The evolution of sexual dimorphism by sexual selection: The separate effects of intrasexual selection and intersexual selection. Evolution 44: 315-331.

Mulder RA. 1997. Extra-group courtship displays and other reproductive tactics of superb fairy-wrens. Aust J Zool 45: 131-143.

Mulder RA, Dunn PO, Cockburn A, Lazenby-Cohen KA, Howell MJ. 1994. Helpers liberate female fairy-wrens from constraints on extra-pair mate choice. Proc Roy Soc B 255: 223-229.

Orians GH. 1969. On the evolution of mating systems in birds and mammals. Am Nat 103: 589-603.

Oring LW, Fleischer RC, Reed JM, Marsden KE. 1992. Cuckoldry through stored sperm in the sequentially polyandrous spotted sandpiper. Nature 359: 631-633.

Parker GA. 1979. Sexual selection and sexual conflict. In Sexual selection and reproductive competition in insects (ed. Blum MS, Blum NA), pp. 123-166. Academic, New York.

Parker GA. 1990. Sperm competition games: Sneaks and extra-pair copulations. Proc Roy Soc B 242: 127-133.

Parker GA. 2006. Sexual conflict over mating and fertilization: An overview. Phil Trans Roy Soc B 361: 235-259.

Parker GA, Birkhead TR. 2013. Polyandry: The history of a revolution. Phil Trans Roy Soc B 368: 20120335.

Pedersen MC, Dunn PO, Whittingham LA. 2006. Extraterritorial forays are related to a male ornamental trait in the common yellowthroat. Anim Behav 72: 479-486.

Petrie M, Kempenaers B. 1998. Extra-pair paternity in birds: Explaining variation between species and populations. Trends Ecol Evol 13: 52-58.

Pizzari T, Wedell N. 2013. The polyandry revolution. Phil Trans Roy Soc B 368: 20120041.

Pizzari T, Cornwallis CK, Lovlie H, Jakobssen S, Birkhead TR. 2003. Sophisticated sperm allocation in male fowl. Nature 426: 70-74.

Reinhardt K, Naylor RA, Siva-Jothy MT. 2009. Ejaculate components delay reproductive senescence while elevating female reproductive rate in an insect. Proc Natl Acad Sci 106: $21743-21747$.

Reynolds JD. 1996. Animal breeding systems. Trends Ecol Evol 11: 68-72.

Rice WR. 1998. Intergenomic conflict, interlocus antagonistic coevolution, and the evolution of reproductive isolation. In Endless forms: Species and speciation (ed. 
Howard DJ, Berlocher SH), pp. 261-270. Oxford University Press, New York.

Rice WR, Holland B. 1997. The enemies within: Intergenomic conflict, interlocus contest evolution (ICE), and the intraspecific red queen. Behav Ecol Sociobiol 41: 1-10.

Rowe L. 1992. Convenience polyandry in a water strider: Foraging conflicts and female control of copulation frequency and guarding duration. Anim Behav 44: 189-202.

Schlicht E, Kempenaers B. 2011 Extra-pair paternity and sexual selection. In From genes to animal behavior (ed. Inoue-Murayama M, Kawamura S, Weiss A), pp. 35-65. Springer, New York.

Schwagmeyer PL, St. Clair RC, Moodie JD, Lamey TC, Schnell GD, Moodie MN. 1999. Species differences in male parental care in birds: A reexamination of correlates with paternity. Auk 116: 487-503.

Sheldon BC. 1994. Male phenotype, fertility, and the pursuit of extra-pair copulations by female birds. Proc Roy Soc B 257: $25-30$.

Sheldon BC. 2000. Differential allocation: Tests, mechanisms and implications. Trends Ecol Evol 15: 397-402.

Sheldon BC. 2002. Relating paternity to paternal care. Proc R Sco 357: 341-350.

Sheldon BC, Ellegren H. 1999. Sexual selection resulting from extrapair paternity in collared flycatchers. Anim Behav 57: 285-298.

Simmons LW. 2005. The evolution of polyandry: Sperm competition, sperm selection, and offspring viability. Ann Rev Ecol Evol Syst 36: 125-146.

Slatyer RA, Mautz BS, Backwell PRY, Jennions MD. 2012. Estimating genetic benefits of polyandry from experimental studies: A meta-analysis. Biol Rev 87: 1-33.
Soltis J, Thomsen R, Matsubayashi K, Takenaka O. 2000. Infanticide by resident males and female counter-strategies in wild Japanese macaques Macaca fuscata. Behav Ecol Sociobiol 48: 195-202.

Trivers RL. 1972. Parental investment and sexual selection. In Sexual selection and descent of man (ed. Campbell B), pp. 136-179. Aldine, Chicago, IL.

Tuttle EM, Pruett-Jones S, Webster M. 1996. Cloacal protuberances and extreme sperm production in Australian fairy-wrens. Proc Roy Soc B 263: 1359-1364.

Webster MS, Pruett-Jones S, Westneat DF, Arnold SJ. 1995. Measuring the effects of pairing success, extra-pair copulations and mate quality on the opportunity for sexual selections. Evolution 49: 1147-1157.

Wedell N, Kvarnemo C, Lessells CM, Tregenza T. 2006. Sexual conflict and life histories. Anim Behav 71: 999-1011.

Westneat DF, Sherman PW. 1993. Parentage and the evolution of parental behavior. Behav Ecol 4: 66-77.

Westneat DF, Stewart IRK. 2003. Extra-pair paternity in birds: Causes, correlates, and conflict. Annu Rev Ecol Syst 34: 365-396.

Westneat DF, Sherman PW, Morton ML. 1990. The ecology and evolution of extra-pair copulations in birds. Curr Ornithol 7: 331-369.

Wolfner MF. 2002. The gifts that keep on giving: Physiological functions and evolutionary dynamics of male seminal proteins in Drosophila. Heredity 88: 85-93.

Zeh JA, Zeh DW. 2001. Reproductive mode and the genetic benefits of polyandry. Anim Behav 61: 1051-1063.

Zeh JA, Zeh DW. 2006. Outbred embryos rescue inbred halfsiblings in mixed-paternity broods of live-bearing females. Nature 439: 201-203. 


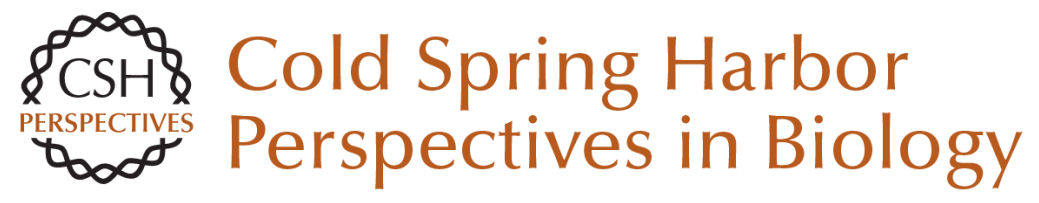

\section{Sexual Conflict Arising from Extrapair Matings in Birds}

Alexis S. Chaine, Robert Montgomerie and Bruce E. Lyon

Cold Spring Harb Perspect Biol 2015; doi: 10.1101/cshperspect.a017590 originally published online January 20, 2015

\section{Subject Collection The Genetics and Biology of Sexual Conflict}

Mechanisms and Evidence of Genital Coevolution: The Roles of Natural Selection, Mate Choice, and Sexual Conflict

Patricia L.R. Brennan and Richard O. Prum

The Evolution of Sexually Antagonistic Phenotypes

Jennifer C. Perry and Locke Rowe

Reproductive Parasitism: Maternally Inherited

Symbionts in a Biparental World

Gregory D.D. Hurst and Crystal L. Frost

Sex-Biased Gene Expression and Sexual Conflict throughout Development

Fiona C. Ingleby, Ilona Flis and Edward H. Morrow

Human Homosexuality: A Paradigmatic Arena for

Sexually Antagonistic Selection?

Andrea Camperio Ciani, Umberto Battaglia and Giovanni Zanzotto

Sexual Conflict Arising from Extrapair Matings in Birds

Alexis S. Chaine, Robert Montgomerie and Bruce E. Lyon

Sexual Conflict and Seminal Fluid Proteins: A

Dynamic Landscape of Sexual Interactions

Laura K. Sirot, Alex Wong, Tracey Chapman, et al.

Conflict on the Sex Chromosomes: Cause, Effect, and Complexity

Judith E. Mank, David J. Hosken and Nina Wedell
Infanticide as Sexual Conflict: Coevolution of

Male Strategies and Female Counterstrategies Ryne A. Palombit

Copulatory Wounding and Traumatic Insemination

Klaus Reinhardt, Nils Anthes and Rolanda Lange

Sexual Conflict in Hermaphrodites

Lukas Schärer, Tim Janicke and Steven A. Ramm

Sexual Conflict and Sperm Competition

Dominic A. Edward, Paula Stockley and David J. Hosken

Sexually Antagonistic Zygotic Drive: A New Form of Genetic Conflict between the Sex

Chromosomes

Urban Friberg and William R. Rice

Sex Chromosome Drive

Quentin Helleu, Pierre R. Gérard and Catherine Montchamp-Moreau

Is Sexual Conflict an "Engine of Speciation"? Sergey Gavrilets

Sexual Cannibalism as a Manifestation of Sexual Conflict

Jutta M. Schneider

For additional articles in this collection, see http://cshperspectives.cshlp.org/cgi/collection/

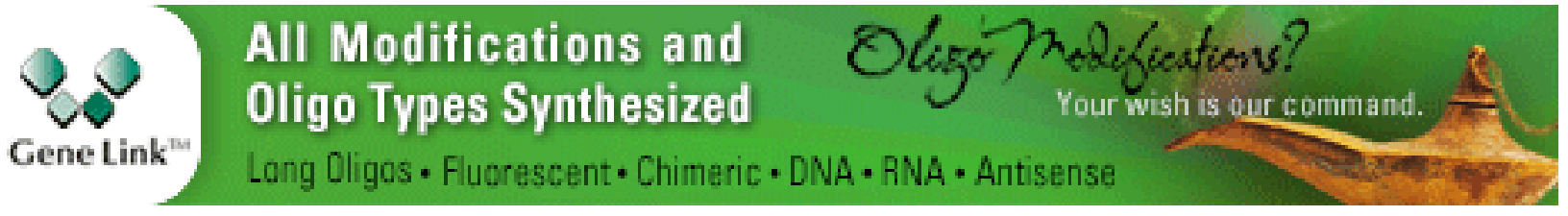

Copyright @ 2015 Cold Spring Harbor Laboratory Press; all rights reserved 
For additional articles in this collection, see http://cshperspectives.cshlp.org/cgi/collection/

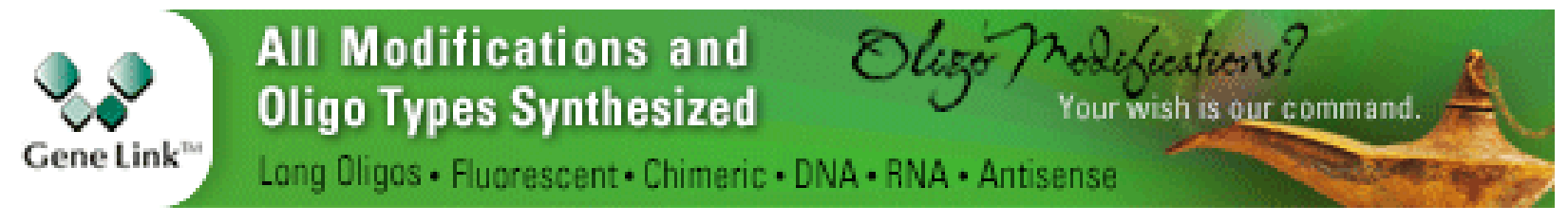

Copyright @ 2015 Cold Spring Harbor Laboratory Press; all rights reserved 